\title{
Sleep, Fatigue, and Depressive Symptoms among Female Nurses with Allergic Rhinitis
}

\author{
Oksoo Kim $^{1}{ }^{1}$, Bohye Kim $^{1}{ }^{1}$, Hyunseon Jeong ${ }^{1}$, Jisun Lee ${ }^{1}\left(\mathbb{D}\right.$ and Heeja Jung ${ }^{2, *(\mathbb{D}}$ \\ 1 College of Nursing, Ewha Womans University, 52, Ewhayeodae-gil, Seodaemun-gu, Seoul 03760, Korea; \\ ohong@ewha.ac.kr (O.K.); bohyekim516@naver.com (B.K.); idadoshi@hotmail.com (H.J.); \\ rollorcoaste@naver.com (J.L.) \\ 2 College of Nursing, Konyang University, 158, Gwanjeodong-ro, Seo-gu, Daejeon 35365, Korea \\ * Correspondence: jhj1215@konyang.ac.kr; Tel.: +82-42-600-8581
}

Citation: Kim, O.; Kim, B.; Jeong, H.; Lee, J.; Jung, H. Sleep, Fatigue, and Depressive Symptoms among Female Nurses with Allergic Rhinitis. Healthcare 2021, 9, 1328. https: / / doi.org/10.3390/healthcare9101328

Academic Editor: Alyx Taylor

Received: 12 July 2021

Accepted: 1 October 2021

Published: 5 October 2021

Publisher's Note: MDPI stays neutral with regard to jurisdictional claims in published maps and institutional affiliations.

Copyright: (c) 2021 by the authors. Licensee MDPI, Basel, Switzerland. This article is an open access article distributed under the terms and conditions of the Creative Commons Attribution (CC BY) license (https:// creativecommons.org/licenses/by/ $4.0 /)$.

\begin{abstract}
Allergic rhinitis (AR) is a common chronic disease that negatively affects physical and mental health. The purpose of this study was to determine the effects of allergic rhinitis on sleep, fatigue, and depressive symptoms among Korean female nurses. This was a cross-sectional study conducted using data from the Korea Nurses' Health Study (KNHS), and a total of 8645 female nurses was selected for the final analysis. The demographic characteristics, Body Mass Index, alcohol consumption, shift work, comorbidities (atopic dermatitis and asthma), self-rated health, sleep disturbance (Jenkins Sleep Questionnaire), fatigue (Chalder Fatigue Scale), and depressive symptoms (Perceived Health Questionnaire-9) were collected. The data were analyzed using chisquare tests, $t$-tests, and hierarchical multiple regression analyses. Participants with allergic rhinitis had significantly greater sleep disturbance, fatigue, and depressive symptoms than those without allergic rhinitis, and allergic rhinitis was a significant factor influencing sleep disturbance and fatigue among the participants after controlling for confounding variables. Therefore, it is imperative to develop effective interventions to manage allergic rhinitis symptoms and improve sleep and fatigue in affected nurses.
\end{abstract}

Keywords: rhinitis; sleep; fatigue; depression; nurses; woman; shift work

\section{Introduction}

Allergic rhinitis (AR) is a common chronic disease affecting $10-40 \%$ of the population worldwide [1]. In the United States, $7.7 \%$ of adults are diagnosed with AR each year [2], while the prevalence of AR among Korean adults is 14.6\% [3]. Exposure to hazardous substances in the workplace may increase the risk of developing AR for healthcare workers [4]. The incidence of AR among nurses has been reported to be $20 \%$ in Pakistan [5]; in Japan, $10.7 \%$ of nurses have asthma; among whom, the incidence of AR was reported to be $54.3 \%$ [6]. AR is a chronic disease that negatively affects sleep, quality of life, and work performance $[7,8]$, resulting in high healthcare and social costs [9].

The main symptoms of AR are nasal itching, sneezing, rhinorrhea, and nasal congestion [10], with nasal obstruction being the symptom most often experienced by AR patients [11]. According to previous studies, adults with AR experience obstructive sleep apnea and sleep-disordered breathing [12,13], as well as prolonged sleep latency, insomnia, sleep disturbances, and daytime dysfunction [14]. In addition, the severity of nasal congestion was reported to be highest during the night and early morning, with increased daytime sleepiness and fatigue [15]. Some studies have reported that patients with seasonal allergies experienced more fatigue than healthy adults [16]. Park et al. [17] suggested that patients with AR and obstructive sleep apnea have a higher level of fatigue than those with only obstructive sleep apnea.

AR can affect mental health, as well as physical health. In adults with AR, the more persistent and severe the symptoms, the higher the degree of depression [17-19]. 
Grosso et al. [20] reported that depression was associated with the failure to control AR symptoms and limitations in daily activities due to the disease. Meanwhile, in another study, a depressed mood was associated with decreased productivity rather than with symptoms of AR [21]. Therefore, the relationship between AR and depression remains unclear, and further research is needed.

Few studies have investigated the effects of AR on physical and mental health specifically among nurses, who are frequently exposed to workplace allergens. Sleep, fatigue, and depression, which have been reported to be related to AR, can negatively affect nurses job performances. Therefore, this study was conducted to determine the effect of AR on sleep disturbance, fatigue, and depressive symptoms among a nationwide cohort of Korean nurses.

\section{Materials and Methods}

\subsection{Study Design, Population, and Setting}

This study is a cross-sectional study conducted using data from the Korea Nurses' Health Study (KNHS), an ongoing web-based cohort study started to identify factors affecting women's health. KNHS, which started in 2013, uses a similar protocol as the NHS3 in the United States but uses a questionnaire customized for Korea [22]. Participants in the Module 1 survey, which was the KNHS baseline survey, included 20,613 female nurses in their reproductive years (i.e., aged $20-45$ years), and these participants were working within one year of the baseline survey. A total of 10,253 female nurses participated in the KNHS Module 8 survey from October 2019 to April 2020. This study targeted 8645 female nurses who participated in the Module 8 survey, except not employed women for 1 year.

\subsection{Measures}

Sleep disturbance was measured using Jenkins Sleep Questionnaire (JSQ) [23]. The tool consists of four items asking participants how many days they have experienced sleep problems in the previous 30 days. The questions include difficulty falling asleep, waking up several times at night, difficulty falling asleep again after waking up at night, and feeling tired after the usual amount of sleep. Each question is measured on a 6-point Likert scale from 0 to 5 : "Not at all (0)", " $1-3$ days (1)", " $4-7$ days (2)", " $8-14$ days (3)", "15-21 days (4)", or "22-30 days (5)". The possible range of scores is $0-20$, and the higher the total score, the higher the degree of sleep disturbance. Cronbach's alpha of the original study was reported to be 0.79 [23], and the Cronbach's alpha of this study was 0.85 .

Fatigue was measured using the Chalder Fatigue Scale (CFS) [24]. This tool consists of 11 items and includes questions about physical changes due to fatigue, decreased thinking ability, and decreased memory. The CFS consists of two subcategories, 7 items for physical fatigue and 4 items for mental fatigue. Each item is measured on a 4-point Likert scale from 0 to 3: "better than usual (0)," "no more than usual (1)," "worse than usual (2)", or "much worse than usual (3)". The possible range of total scores is $0-33$, with $0-21$ for physical fatigue and 0-12 for mental fatigue. The higher the score, the higher the level of fatigue. The Cronbach's alpha of the original tool was 0.90 [24] and that of this study was 0.90.

Depressive symptoms were measured using the Patient Health Questionnaire (PHQ-9) [25]. The 9-item PHQ-9 measures displeasure, fatigue, appetite change, guilt or worthlessness, decreased concentration, slow movement or restlessness, and suicidal ideation. Each item is measured on a 4-point Likert scale: "not at all (0)", "several days (1)", "more than half of the days (2)", or "nearly every day (3)". The possible range for the total score is $0-27$, and the higher the score, the higher the degree of depressive symptoms. The Cronbach's alpha of the original tool was reported as 0.86 [25], and the Cronbach's alpha in this study was 0.86 .

Baseline characteristics, comorbidities, and self-rated health were included as covariates based on a literature review to determine the effect of AR on sleep disturbance, fatigue, and depressive symptoms. The baseline characteristics included age, education 
level, marital status, body mass index (BMI), alcohol consumption, and shift work. The comorbidities included atopic dermatitis and asthma. Sleep disturbance, fatigue, and depressive symptoms have been reported to affect each other [26-28], so they were included as confounders in each regression model.

\subsection{Ethical Considerations}

This study was conducted after approval by the institutional review board for the ethical protection of participants (IRB No. 201904-0012-03). Anonymity and confidentiality were assured, and informed consent was obtained from the participants as part of the online survey.

\subsection{Data Analysis}

A data analysis was performed using SPSS version 26.0 (IBM Corp., Armonk, NY, USA). The chi-square test and $t$-test were used to analyze and confirm the differences in the baseline characteristics and comorbidities between the AR group and the non-AR group. The $t$-tests were used to check the differences in the degree of sleep disturbance, fatigue, and depressive symptoms between the AR group and the no AR group.

Finally, hierarchical multiple regression analyses were performed to examine the effect of AR on the sleep disturbance, fatigue, and depressive symptoms. Hierarchical multiple regression was utilized using four stage models. The stage 1 model included the AR status. The stage 2 model included age, level of education, marital status, BMI, alcohol consumption, and shift work, while the stage 3 model included atopic dermatitis and asthma as the confounding variables. In stage 4 , each model included sleep disturbance, fatigue, or depressive symptoms as the confounders, as well as self-rated health. The threshold of statistical significance for this study was $p<0.05$.

\section{Results}

\subsection{Baseline Characteristics according to Allergic Rhinitis Status}

Of the 8645 study participants, the prevalence of AR was $20.9 \%(n=1808)$. There were significant differences in the age $\left(\chi^{2}=10.16, p=0.017\right)$, atopic dermatitis $\left(\chi^{2}=206.69\right.$, $p<0.001)$, asthma $\left(\chi^{2}=252.02, p<0.001\right)$, and self-rated health $\left(\chi^{2}=44.70, p<0.001\right)$ between the AR and the no AR groups (Table 1). In the AR group, the largest proportion of participants (59.1\%) was in the 30-39 age group. In the AR group, $15.2 \%$ of the participants had atopic dermatitis and $7.0 \%$ had asthma, which were both higher compared to the no AR group. The participants who rated their health as poor were $17.0 \%$ in the AR group and $12.4 \%$ in the no AR group, indicating that the level of self-rated health was lower in the AR group (Table 1).

Table 1. Baseline characteristics according to allergic rhinitis $(N=8645)$.

\begin{tabular}{|c|c|c|c|c|c|c|c|}
\hline \multirow{2}{*}{ Characteristics } & \multirow{2}{*}{ Category } & \multicolumn{2}{|c|}{$\begin{array}{c}\text { No AR } \\
(N=6837) \\
\end{array}$} & \multicolumn{2}{|c|}{$\begin{array}{c}\text { AR } \\
(N=1808)\end{array}$} & \multirow{2}{*}{$\operatorname{tor} x^{2}$} & \multirow{2}{*}{$p$} \\
\hline & & $\mathbf{n}$ & $\%$ & n & $\%$ & & \\
\hline \multirow{5}{*}{ Age, years } & $\leq 29$ & 1217 & 17.8 & 327 & 18.1 & 10.16 & 0.017 \\
\hline & $30-39$ & 3829 & 56.0 & 1069 & 59.1 & & \\
\hline & $40-49$ & 1651 & 24.1 & 373 & 20.6 & & \\
\hline & $\geq 50$ & 140 & 2.0 & 39 & 2.2 & & \\
\hline & $\overline{\mathrm{M}} \pm \mathrm{SD}$ & \multicolumn{2}{|c|}{$35.58 \pm 6.16$} & \multicolumn{2}{|c|}{$35.30 \pm 5.85$} & 1.82 & 0.069 \\
\hline \multirow{3}{*}{ Education level } & 3-year college & 1235 & 18.1 & 339 & 18.8 & 2.55 & 0.280 \\
\hline & 4-year college & 4289 & 62.7 & 1151 & 63.7 & & \\
\hline & Master or higher & 1313 & 19.2 & 318 & 17.6 & & \\
\hline \multirow{6}{*}{$\begin{array}{c}\text { Marital status } \\
\text { BMI }\end{array}$} & Single or others & 2551 & 37.3 & 646 & 35.7 & 1.54 & 0.218 \\
\hline & Married & 4286 & 62.7 & 1162 & 64.3 & & \\
\hline & Normal (18.5-23kg/m²) & 4068 & 59.5 & 1037 & 57.4 & 5.35 & 0.069 \\
\hline & Underweight $\left(<18.5 \mathrm{~kg} / \mathrm{m}^{2}\right)$ & 526 & 7.7 & 127 & 7.0 & & \\
\hline & Overweight $\left(\geq 23 \mathrm{~kg} / \mathrm{m}^{2}\right)$ & 2243 & 32.8 & 644 & 35.6 & & \\
\hline & $\mathrm{M} \pm \mathrm{SD}$ & \multicolumn{2}{|c|}{$22.21 \pm 3.24$} & \multicolumn{2}{|c|}{$22.41 \pm 3.36$} & -2.23 & 0.026 \\
\hline
\end{tabular}


Table 1. Cont.

\begin{tabular}{|c|c|c|c|c|c|c|c|}
\hline \multirow{2}{*}{ Characteristics } & \multirow{2}{*}{ Category } & \multicolumn{2}{|c|}{$\begin{array}{c}\text { No AR } \\
(N=6837)\end{array}$} & \multicolumn{2}{|c|}{$\begin{array}{c}\text { AR } \\
(N=1808)\end{array}$} & \multirow{2}{*}{$\operatorname{tor} x^{2}$} & \multirow{2}{*}{$p$} \\
\hline & & $\mathbf{n}$ & $\%$ & $\mathbf{n}$ & $\%$ & & \\
\hline \multirow{2}{*}{ Alcohol consumption } & No & 1928 & 28.2 & 487 & 26.9 & 1.13 & 0.302 \\
\hline & Yes & 4909 & 71.8 & 1321 & 73.1 & & \\
\hline \multirow{2}{*}{ Shift work } & No & 3512 & 51.4 & 953 & 52.7 & 1.03 & 0.315 \\
\hline & Yes & 3325 & 48.6 & 855 & 47.3 & & \\
\hline \multirow{2}{*}{ Atopic dermatitis } & No & 6478 & 94.7 & 1534 & 84.8 & 206.69 & $<0.001$ \\
\hline & Yes & 359 & 5.3 & 274 & 15.2 & & \\
\hline \multirow{2}{*}{ Asthma } & No & 6777 & 99.1 & 1682 & 93.0 & 252.02 & $<0.001$ \\
\hline & Yes & 60 & 0.9 & 126 & 7.0 & & \\
\hline \multirow{3}{*}{ Self-rated health } & Good & 2674 & 39.1 & 577 & 31.9 & 44.70 & $<0.001$ \\
\hline & Fair & 3316 & 48.5 & 923 & 51.1 & & \\
\hline & Poor & 847 & 12.4 & 308 & 17.0 & & \\
\hline
\end{tabular}

$\mathrm{AR}=$ Allergic Rhinitis, $\mathrm{BMI}=$ Body Mass Index, $\mathrm{M}=$ Mean, and SD = Standard Deviation .

3.2. Sleep Disturbance, Fatigue, and Depressive Symptoms among Participants with and without Allergic Rhinitis

Table 2 shows the differences in sleep disturbance, fatigue, and depressive symptoms between the AR group and the no AR group. Significant differences were found in the sleep disturbance, fatigue, and depressive symptoms according to the AR status. The mean score of sleep disturbance in the AR group was 5.42 ( $\mathrm{SD}=4.81$ ), which was higher than that of the no AR group $(t=-7.28, p<0.001)$. The mean score of total fatigue in the AR group, 17.44 ( $\mathrm{SD}=5.74)$, was also higher than that of the no AR group $(\mathrm{t}=-8.39, p<0.001)$. Participants with AR had significantly higher depressive symptoms $(\mathrm{M} \pm \mathrm{SD}=5.41 \pm 4.33)$ than those without AR $(t=-5.48, p<0.001)$ (Table 2).

Table 2. Sleep disturbance, fatigue, and depressive symptoms according to allergic rhinitis $(N=8645)$.

\begin{tabular}{|c|c|c|c|c|}
\hline \multirow{2}{*}{ Characteristics } & $\begin{array}{c}\text { No AR } \\
(N=6837)\end{array}$ & $\begin{array}{c}\text { AR } \\
(N=1808)\end{array}$ & \multirow{2}{*}{$\mathbf{t}$} & \multirow{2}{*}{$p$} \\
\hline & $\mathbf{M} \pm \mathbf{S D}$ & $\mathbf{M} \pm \mathbf{S D}$ & & \\
\hline Sleep disturbance & $4.51 \pm 4.34$ & $\begin{array}{c}5.42 \pm 4.81 \\
\text { Fatigue }\end{array}$ & -7.28 & $<0.001$ \\
\hline Physical fatigue & $11.01 \pm 4.02$ & $11.87 \pm 3.74$ & -8.63 & $<0.001$ \\
\hline Mental fatigue & $5.15 \pm 2.62$ & $5.57 \pm 2.63$ & -6.05 & $<0.001$ \\
\hline Total & $16.16 \pm 6.02$ & $17.44 \pm 5.74$ & -8.39 & $<0.001$ \\
\hline Depressive symptoms & $4.81 \pm 4.17$ & $5.41 \pm 4.33$ & -5.48 & $<0.001$ \\
\hline
\end{tabular}

$\mathrm{AR}=$ Allergic Rhinitis, $\mathrm{M}=$ Mean, and $\mathrm{SD}=$ Standard Deviation.

\subsection{The Effect of Allergic Rhinitis on Sleep Disturbance, Fatigue, and Depressive Symptoms}

Hierarchical multiple regression analyses were performed to identify the effect of allergic rhinitis on the sleep disturbance, fatigue, and depressive symptoms (Tables 3-5). The VIFs were 10 or less, and the tolerance value range 1.0 or less in all of the models; therefore, there was no problem with multicollinearity.

From the multiple regression analyses, AR was identified as a significant factor influencing sleep disturbance $(\beta=0.03, p<0.001)$ and fatigue $(\beta=0.03, p<0.001)$ among the participants after controlling for confounders. However, AR was not found to have an influence on depressive symptoms. The explanatory power of model 4 was $35.4 \%$ $(\mathrm{F}=339.81, p<0.001)$ for sleep disturbance and $46.3 \%(\mathrm{~F}=533.39, p<0.001)$ for fatigue. 
Table 3. Effects of allergic rhinitis on sleep disturbance $(N=8645)$.

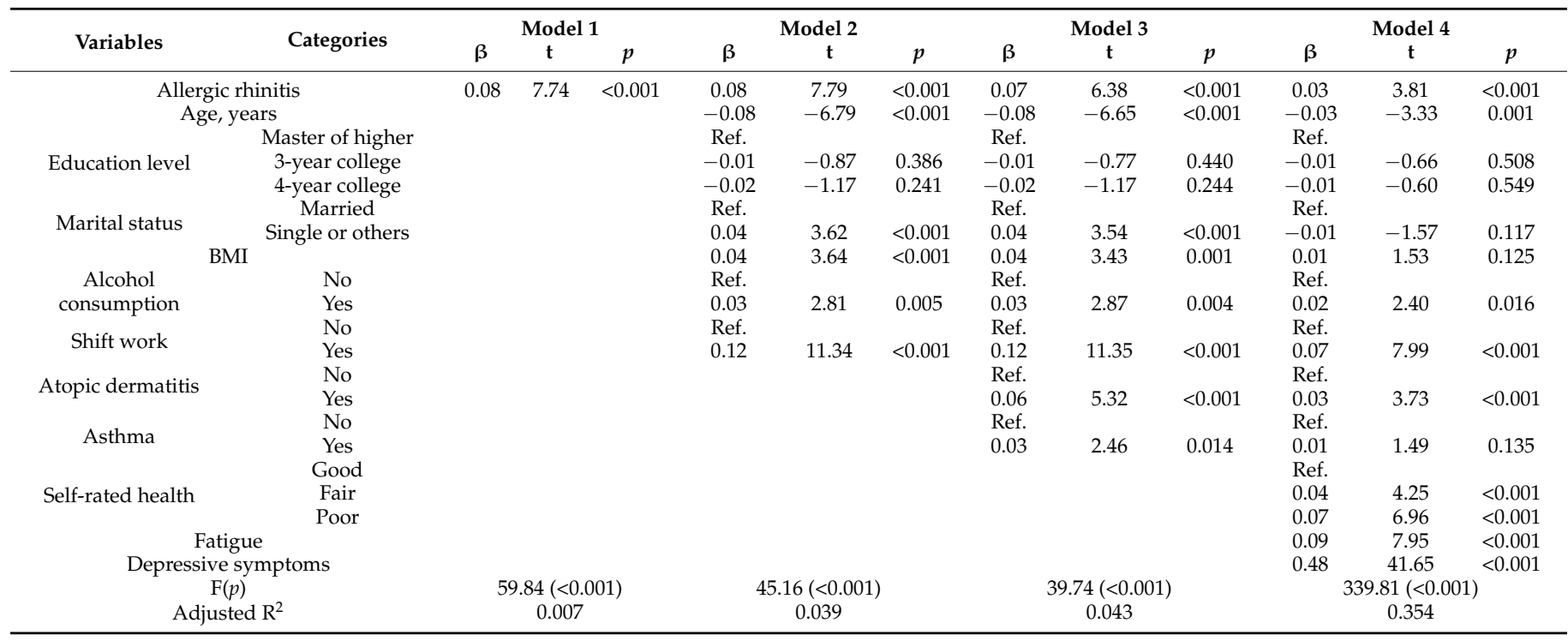

BMI = Body Mass Index and Ref. = Reference .

Table 4. Effects of allergic rhinitis on fatigue $(N=8645)$.

\begin{tabular}{|c|c|c|c|c|c|c|c|c|c|c|c|c|c|}
\hline \multirow{2}{*}{ Variables } & \multirow{2}{*}{ Categories } & \multicolumn{3}{|c|}{ Model 1} & \multicolumn{3}{|c|}{ Model 2} & \multicolumn{3}{|c|}{ Model 3} & \multicolumn{3}{|c|}{ Model 4} \\
\hline & & $\beta$ & $t$ & $p$ & $\beta$ & t & $p$ & $\beta$ & $t$ & $p$ & $\beta$ & $\mathbf{t}$ & $p$ \\
\hline \multicolumn{2}{|c|}{ Allergic rhinitis } & 0.09 & 8.16 & $<0.001$ & 0.09 & 8.25 & $<0.001$ & 0.08 & 7.30 & $<0.001$ & 0.03 & 4.27 & $<0.001$ \\
\hline \multicolumn{2}{|c|}{ Age, years } & & & & -0.04 & -3.48 & 0.001 & -0.04 & -3.38 & 0.001 & 0.00 & 0.37 & 0.712 \\
\hline & Master of higher & & & & Ref. & & & Ref. & & & Ref. & & \\
\hline \multirow[t]{2}{*}{ Education level } & 3-year college & & & & 0.00 & -0.34 & 0.737 & 0.00 & -0.28 & 0.782 & 0.00 & -0.34 & 0.732 \\
\hline & 4-year college & & & & -0.02 & -1.69 & 0.090 & -0.02 & -1.69 & 0.091 & -0.02 & -1.63 & 0.103 \\
\hline \multirow{2}{*}{ Marital status } & Married & & & & Ref. & & & Ref. & & & Ref. & & \\
\hline & Single or others & & & & -0.03 & -3.02 & 0.003 & -0.04 & -3.08 & 0.002 & -0.11 & -13.18 & $<0.001$ \\
\hline \multicolumn{2}{|l|}{ 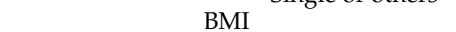 } & & & & -0.03 & -2.74 & 0.006 & -0.03 & -2.87 & 0.004 & -0.07 & -9.14 & $<0.001$ \\
\hline Alcohol & No & & & & Ref. & & & Ref. & & & Ref. & & \\
\hline consumption & Yes & & & & 0.01 & 0.85 & 0.394 & 0.01 & 0.88 & 0.378 & 0.00 & 0.31 & 0.756 \\
\hline \multirow{2}{*}{ Shift work } & No & & & & Ref. & & & Ref. & & & Ref. & & \\
\hline & Yes & & & & 0.09 & 8.36 & $<0.001$ & 0.09 & 8.36 & $<0.001$ & 0.02 & 2.93 & 0.003 \\
\hline \multirow{2}{*}{ Atopic dermatitis } & No & & & & & & & Ref. & & & Ref. & & \\
\hline & Yes & & & & & & & 0.04 & 3.31 & 0.001 & 0.00 & 0.59 & 0.554 \\
\hline \multirow{3}{*}{ Asthma } & No & & & & & & & Ref. & & & Ref. & & \\
\hline & Yes & & & & & & & 0.02 & 1.43 & 0.153 & 0.00 & -0.43 & 0.664 \\
\hline & Good & & & & & & & & & & Ref. & & \\
\hline \multirow[t]{2}{*}{ Self-rated health } & Fair & & & & & & & & & & 0.20 & 23.23 & $<0.001$ \\
\hline & Poor & & & & & & & & & & 0.22 & 23.72 & $<0.001$ \\
\hline \multirow{2}{*}{\multicolumn{2}{|c|}{$\begin{array}{l}\text { Sleep disturbance } \\
\text { Depressive symptoms }\end{array}$}} & & & & & & & & & & 0.08 & 7.95 & $<0.001$ \\
\hline & & & & & & & & & & & 0.52 & 51.86 & $<0.001$ \\
\hline \multirow{2}{*}{\multicolumn{2}{|c|}{$\begin{array}{c}\mathrm{F}(p) \\
\text { Adiusted } \mathrm{R}^{2}\end{array}$}} & \multicolumn{3}{|c|}{$66.58(<0.001)$} & \multicolumn{3}{|c|}{$21.44(<0.001)$} & \multicolumn{3}{|c|}{$18.49(<0.001)$} & \multicolumn{3}{|c|}{$533.39(<0.001)$} \\
\hline & & \multicolumn{3}{|c|}{0.008} & \multicolumn{3}{|c|}{0.019} & \multicolumn{3}{|c|}{0.020} & \multicolumn{3}{|c|}{0.463} \\
\hline
\end{tabular}

BMI = Body Mass Index and Ref. = Reference .

Among the control variables, the factors affecting sleep disturbance were age $(\beta=-0.03$, $p=0.001)$, alcohol consumption $(\beta=0.02, p=0.016)$, shift work $(\beta=0.07, p<0.001)$, atopic dermatitis ( $\beta=0.03, p<0.001$ ), self-rated health (fair $\beta=0.04, p<0.001$; poor $\beta=0.07, p<0.001$ ), fatigue $(\beta=0.09, p<0.001)$, and depressive symptoms $(\beta=0.48, p<0.001)$. The confounders affecting fatigue were marital status ( $\beta=-0.11, p<0.001)$, BMI $(\beta=-0.07, p<0.001)$, shift work ( $\beta=0.02, p=0.003$ ), self-rated health (fair $\beta=0.20, p<0.001$; poor $\beta=0.22, p<0.001$ ), sleep disturbance $(\beta=0.08, p<0.001)$, and depressive symptoms $(\beta=0.52, p<0.001)$. Lastly, age $(\beta=-0.05, p<0.001)$, marital status $(\beta=0.11, p<0.001)$, BMI $(\beta=0.04, p<0.001)$, self-rated health (poor $\beta=0.06, p<0.001$ ), sleep disturbance $(\beta=0.35, p<0.001$ ), and fatigue ( $\beta=0.46, p<0.001$ ) increased the risk of depressive symptoms (Tables $3-5$ ). 
Table 5. Effects of allergic rhinitis on depressive symptoms $(N=8645)$.

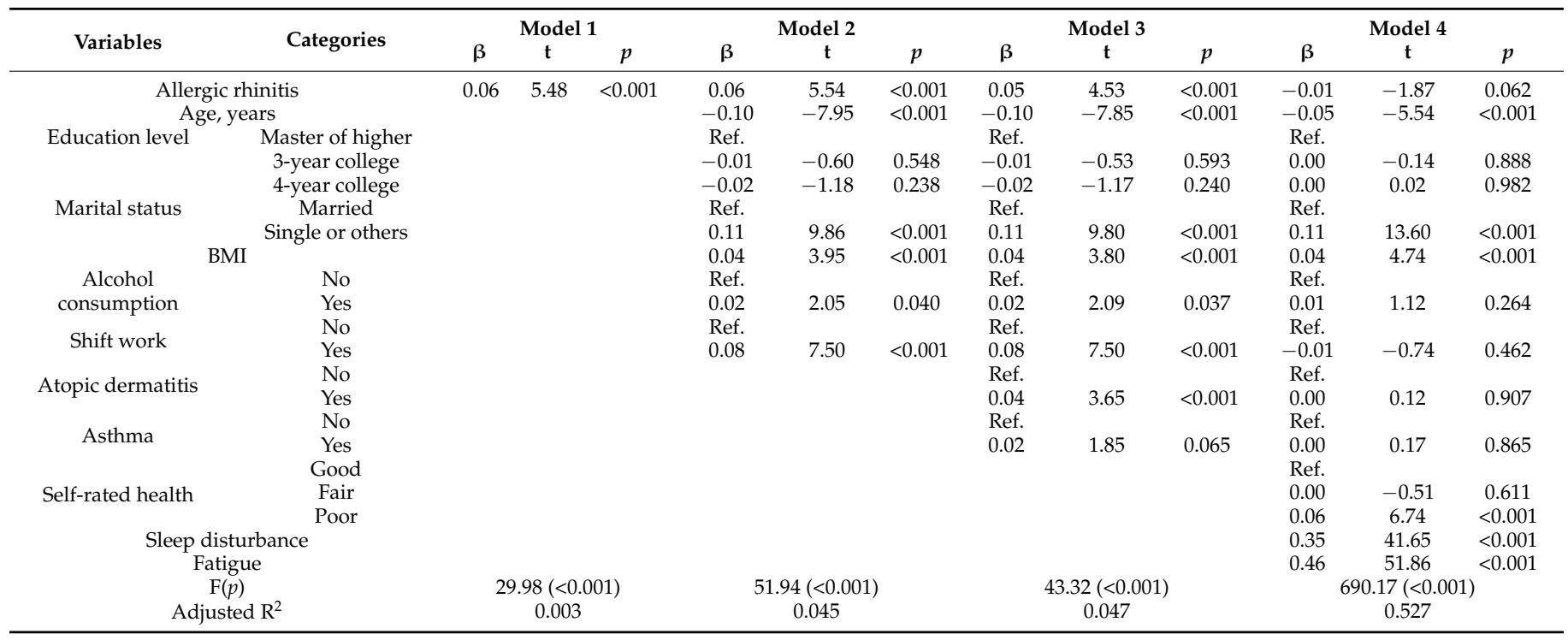

BMI = Body Mass Index and Ref. = Reference .

\section{Discussion}

The present study investigated the prevalence of AR among Korean female nurses to determine the associations between AR and sleep disturbances, fatigue, and depressive symptoms by analyzing the data from the Korea Nurses' Health Study. The results revealed that the prevalence of AR among Korean female nurses was $20.9 \%$, which was slightly lower than the $24.5 \%$ prevalence among Korean females aged 20-29 years old that was identified through data from the 5th Korea National Health and Nutrition Examination Survey (2010-2012) [29]. However, considering that the prevalence of AR has been found to peak between 20 and 29 years of age and then gradually decrease [29], it may be that the prevalence of AR was relatively low in this study because females aged 30 years or older accounted for $82.1 \%$ of the participants.

Few studies have been conducted on the prevalence of AR among nurses. A study involving nurses at university hospitals in Thailand reported the prevalence of AR among nurses to be $7.9 \%$ [30], and a study involving healthcare workers at university hospitals reported the prevalence of AR among healthcare workers to be approximately $20 \%$ [5]. Both rates were lower than that of the present study. However, because the prevalence of AR can vary greatly depending on sex, race, and age [29], further research is needed to determine and compare the prevalence of AR in female nurses of varying races and ages.

In the present study, when the confounding variables were controlled, AR was significantly associated with sleep disturbances. Previous studies on the associations between AR and sleep disturbances have shown relatively consistent results. A study in the United States involving 5563 adults aged 18 years or older demonstrated a significant association between AR and poor sleep parameters, including insomnia [14]. In addition, a large Spanish cohort study involving adults aged 18 years or older found that AR symptoms were significantly associated with poor sleep quality [19]. Nurses have poor sleep quality due to the nature of their work compared to those in other occupations [31], and AR symptoms can worsen nurses' sleep problems. Sleep disturbances can weaken the concentration during the performance of nursing tasks, lower the productivity of nursing care, and negatively affect the quality of nursing care. Therefore, individual efforts, in addition to organizational attention and support for the management of AR symptoms among nurses, are needed.

The results of the present study revealed that, with the confounding variables controlled, AR was significantly associated with fatigue. This result is similar to the results of previous studies regarding the association between AR and fatigue. Specifically, one study on the association between AR and fatigue among patients with obstructive sleep apnea 
(OSA) [17] showed that fatigue was significantly higher in the OSA-AR group compared with the OSA group. In addition, another study on the effects of AR treatment on sexual ability and fatigue [32] found that the AR treatment reduced fatigue from $62.5 \%$ to $22.9 \%$ in female subjects and from $54.2 \%$ to $35.4 \%$ in male subjects. These results suggest that having $\mathrm{AR}$ may be a major factor in the experience of fatigue and that the ineffective management of AR symptoms may worsen fatigue among nurses who already have higher mental and physical fatigue due to the nature of their work [33]. The studies conducted on the association between AR and fatigue among nurses have been homogeneous. However, considering that the high prevalence of AR and high levels of fatigue among nurses significantly affect patient safety and the quality of nursing care [33], policies and measures that support AR symptom management are needed at the hospital level.

The present study found no significant association between AR and depressive symptoms. This finding contradicts that of a systematic review on the association between allergic disorders and the risk of depression that showed a higher risk of depression among patients with AR [34] and that of a Spanish cohort study that demonstrated an association between the severity of AR and depression [18]. In addition, Grosso et al. [20] reported that depression was significantly associated with a greater risk of AR symptom exacerbation. One possible reason for the inconsistency between the results of these previous studies and the present study may be differences in the severity of the AR symptoms. However, owing to the limitations in the data, the severity of the AR symptoms could not be identified in this study. Therefore, future studies on the severity of AR are warranted.

Finally, among the general characteristics of the participants, shift work was found to be significantly associated with sleep disturbances and fatigue. Previous studies have consistently reported that shift work negatively affects the extent of sleep disturbances and fatigue experienced among nurses $[31,33,35]$. The present study found that AR significantly affects sleep and fatigue, and shift work could be a factor contributing to sleep disturbance and fatigue among the nurses diagnosed with AR. Therefore, nurse managers should make more of an effort to reduce the harmful effects of shift work among nurses. In addition, measures should be taken to effectively reduce sleep disturbance and fatigue in nurses diagnosed with AR who perform shift work.

The present study found that AR negatively affects sleep and fatigue among Korean female nurses. Nurses can be exposed to various allergens, such as drugs, antiseptics, and latex gloves, at work, and such occupational exposures may aggravate their AR symptoms. Therefore, organizational support should be provided so that nurses are not unnecessarily exposed to allergens during work. Efforts made by nurse managers, such as to identify the detailed occupational history of nurses with AR and agents that nurses may be exposed to during work and to develop and implement safety guidelines for reducing harmful exposure $[4,10]$, are considered forms of organizational support.

This study is noteworthy in that it is the first to examine the associations between $\mathrm{AR}$ and sleep disturbances, fatigue, and depression among female nurses. In addition, the results will aid in the development and implementation of health promotion activities among Korean nurses, because the study population included nurses working at hospitals nationwide. It may also be possible to extend these health promotion activities to females in the general population, because AR was found to be associated with sleep disturbances and fatigue even after controlling for the nature of nursing work. Despite its strengths, the present study had two limitations that should be addressed. First, the duration of the disease could not be determined due to limitations in the data used. Second, the present study did not identify the severity of the AR symptoms. Considering these limitations, future studies that investigate the effects of AR on sleep disturbances, fatigue, and depression are warranted.

\section{Conclusions}

The present study analyzed the associations between AR and sleep disturbances, fatigue, and depressive symptoms among Korean nurses. The results indicated that, 
after adjustment for the general and work-related characteristics of the participants, AR was significantly associated with sleep disturbances and fatigue but not with depressive symptoms. Nurses have high levels of sleep disturbance and fatigue due to the nature of their work compared to those in other occupations, and these issues are likely to be compounded in nurses with AR. Therefore, nurse managers should pay special attention to these situations and develop measures that prevent nurses diagnosed with AR from being unnecessarily exposed to allergens at work.

Author Contributions: Conceptualization, O.K.; methodology, B.K.; formal analysis, J.L.; investigation, H.J. (Hyunseon Jeong); writing—original draft preparation, O.K., B.K., H.J. (Hyunseon Jeong), J.L., and H.J. (Heeja Jung); writing—review and editing, H.J. (Heeja Jung); supervision, O.K.; and project administration, O.K. All authors have read and agreed to the published version of the manuscript.

Funding: This research was funded by the Korea Centers for Disease Control and Prevention (KCDC) (2019-ER7101-00).

Institutional Review Board Statement: This study was conducted according to the guidelines of the Declaration of Helsinki and approved by the Institutional Review Board of Ewha Woman's University (IRB No.: EWHA-201904-0012-03).

Informed Consent Statement: Informed consent was obtained from all participants involved in the study.

Data Availability Statement: The datasets generated and analyzed during the current study are not publicly available, because this government data needs time for data clearing and the establishment of guidelines. The Korea Centers for Disease Control and Prevention is planning on opening this data to the public in the future.

Conflicts of Interest: The authors declare that they have no conflicts of interest to report.

\section{References}

1. Brożek, J.L.; Bousquet, J.; Agache, I.; Agarwal, A.; Bachert, C.; Bosnic-Anticevich, S.; Brignardello-Petersen, R.; Walter Canonica, G.; Casale, T.; Chavannes, N.H.; et al. Allergic rhinitis and its impact on asthma (ARIA) guidelines-2016 revision. J. Allergy Clin. Immunol. 2017, 140, 950-958. [CrossRef] [PubMed]

2. Center for Disease Control and Prevention. Summary Health Statistics: National Health Interview Survey. 2018. Available online: https:/ / www.cdc.gov/nchs/fastats/allergies.htm (accessed on 30 June 2021).

3. Keum, J.H.; Shin, J.Y.; Sohn, K.J. Socioeconomic status and allergic rhinitis in Korean adults: The 2010-2012 Korea National Health and Nutrition Examination Survey. Korean J. Fam. Pract. 2016, 60, 504-511. [CrossRef]

4. Mazurek, J.M.; Weissman, D.N. Occupational respiratory allergic diseases in healthcare workers. Curr. Allergy Asthma Rep. 2016, 16, 77. [CrossRef] [PubMed]

5. Siddiqui, M.I.; Dhanani, R.; Moiz, H. Prevalence of allergic rhinitis among healthcare workers and its impact on their work: A cross-sectional survey at a tertiary healthcare centre in Pakistan. J. Paki. Med. Assoc. 2020, 70, 1432-1435. [CrossRef]

6. Watanabe, M.; Kurai, J.; Sano, H.; Torai, S.; Yanase, H.; Funakoshi, T.; Fukada, A.; Hayakway, S.; Fitano, H.; Shimizu, E. Prevalence of allergic rhinitis based on the SACRA questionnaire among Japanese nursing professionals with asthma. J. Med. Investig. 2016, 63, 108-113. [CrossRef]

7. Liu, J.; Zhang, X.; Zhao, Y.; Wang, Y. The association between allergic rhinitis and sleep: A systematic review and meta-analysis of observational studies. PLoS ONE 2020, 15, e0228533. [CrossRef]

8. Roger, A.; Arcalá Campillo, E.; Torres, M.C.; Millan, C.; Jáuregui, I.; Mohedano, E.; Liñan, S.; Verdu, P.; Rubira, N.; Santaolalla, M.; et al. Reduced work/academic performance and quality of life in patients with allergic rhinitis and impact of allergen immunotherapy. Allergy Asthma Clin. Immunol. 2016, 12, 40. [CrossRef]

9. Colás, C.; Brosa, M.; Antón, E.; Montoro, J.; Navarro, A.; Dordal, M.T.; Dávila, I.; Fernández-Parra, B.; Ibáñez, M.D.P.; Lluch-Bernal, M. Estimate of the total costs of allergic rhinitis in specialized care based on real-world data: The FERIN Study. Allergy 2017, 72, 959-966. [CrossRef] [PubMed]

10. Seidman, M.D.; Gurgel, R.K.; Lin, S.Y.; Schwartz, S.R.; Baroody, F.M.; Bonner, J.R.; Dawson, D.E.; Dkyewicz, M.S.; Hackell, J.M.; Han, J.K.; et al. Clinical practice guideline: Allergic rhinitis. Otorhinolaryngol. Head Neck Surg. 2015, 152, S1-S43. [CrossRef] [PubMed]

11. Jaruvongvanich, V.; Mongkolpathumrat, P.; Chantaphakul, H.; Klaewsongkram, J. Extranasal symptoms of allergic rhinitis are difficult to treat and affect quality of life. Allergol. Int. 2016, 65, 199-203. [CrossRef]

12. Cao, Y.; Wu, S.; Zhang, L.; Yang, Y.; Cao, S.; Li, Q. Association of allergic rhinitis with obstructive sleep apnea: A meta-analysis. Medicine 2018, 97, e13783. [CrossRef] [PubMed] 
13. Dalewski, B.; Kamińska, A.; Syrico, A.; Kałdunska, A.; Pałka, Ł.; Sobolewska, E. The Usefulness of Modified Mallampati Score and CT Upper Airway Volume Measurements in Diagnosing OSA among Patients with Breathing-Related Sleep Disorders. Appl. Sci. 2021, 11, 3764. [CrossRef]

14. Roxbury, C.R.; Qiu, M.; Shargorodsky, J.; Lin, S.Y. Association between allergic rhinitis and poor sleep parameters in U.S. adults. Int. Forum Allergy Rhinol. 2018, 8, 1098-1106. [CrossRef] [PubMed]

15. Thompson, A.; Sardana, N.; Craig, T.J. Sleep impairment and daytime sleepiness in patients with allergic rhinitis: The role of congestion and inflammation. Ann. Allergy Asthma Immunol. 2013, 111, 446-451. [CrossRef] [PubMed]

16. Tamm, S.; Cervenka, S.; Forsberg, A.; Estelius, J.; Grunewald, J.; Gyllfors, P.; Karshikoff, B.; Kosek, E.; Lampa, J.; Lensmar, C.; et al. Evidence of fatigue, disordered sleep and peripheral inflammation, but not increased brain TSPO expression, in seasonal allergy: A [11C] PBR28 PET study. Brain Behav. Immun. 2018, 68, 146-157. [CrossRef]

17. Park, C.E.; Shin, S.Y.; Lee, K.H.; Cho, J.S.; Kim, S.W. The effect of allergic rhinitis on the degree of stress, fatigue and quality of life in OSA patients. Eur. Arch. Otorhinolaryngol. 2012, 269, 2061-2064. [CrossRef] [PubMed]

18. Kim, D.H.; Han, K.; Kim, S.W. Relationship between allergic rhinitis and mental health in the general Korean adult population. Allergy Asthma Immunol. Res. 2016, 8, 49-54. [CrossRef]

19. Muñoz-Cano, R.; Ribó, P.; Araujo, G.; Giralt, E.; Sanchez-Lopez, J.; Valero, A. Severity of allergic rhinitis impacts sleep and anxiety: Results from a large Spanish cohort. Clin. Transl. Allergy 2018, 8, 23. [CrossRef] [PubMed]

20. Grosso, A.; Pesce, G.; Marcon, A.; Piloni, D.; Albicini, F.; Gini, E.; Marchetii, P.; Battaglia, S.; Ferrari, M.; Fois, A.; et al. Depression is associated with poor control of symptoms in asthma and rhinitis: A population-based study. Respir. Med. 2019, 155, 6-12. [CrossRef]

21. Campbell, A.P.; Hoehle, L.P.; Phillips, K.M.; Caradonna, D.S.; Gray, S.T.; Sedaghat, A.R. Depressed mood is associated with loss of productivity in allergic rhinitis. Allergy 2018, 73, 1141-1144. [CrossRef]

22. Kim, O.; Ahn, Y.; Lee, H.Y.; Jang, H.J.; Kim, S.; Lee, J.E.; Jung, H.; Cho, E.; Lim, J.-Y.; Kim, M.-J.; et al. The Korea nurses' health study: A prospective cohort study. J. Womens Health 2017, 26, 89-899. [CrossRef]

23. Jenkins, C.D.; Stanton, B.-A.; Niemcryk, S.J.; Rose, R.M. A scale for the estimation of sleep problems in clinical research. J. Clin. Epidemiol. 1988, 41, 313-321. [CrossRef]

24. Chalder, T.; Berelowitz, G.; Pawlikowska, T.; Watts, L.; Wessely, S.; Wright, D.; Wallace, E.P. Development of a fatigue scale. J. Psychosom. Res. 1993, 37, 147-153. [CrossRef]

25. Kroenke, K.; Spitzer, R.L.; Williams, J.B.W. The PHQ-9. J. Gen. Intern. Med. 2001, 16, 606-613. [CrossRef]

26. Celik, S.; Tasdemir, N.; Kurt, A.; Ilgezdi, E.; Kubalas, O. Fatigue in intensive care nurses and related factors. Int. J. Occup. Environ. Med. 2017, 8, 199-206. [CrossRef] [PubMed]

27. Kim, B.; Jung, H.; Kim, J.; Lee, J.; Kim, O. Depressive symptoms and sleep disturbance in female nurses with atopic dermatitis: The Korea Nurses' Health Study. Int. J. Environ. Res. Public Health 2020, 17, 2743. [CrossRef] [PubMed]

28. Saleh, A.M.; Awadalla, N.J.; El-masri, Y.M.; Sleem, W.F. Impacts of nurses' circadian rhythm sleep disorders, fatigue, and depression on medication administration errors. Egypt. J. Chest Dis. Tuberc. 2014, 63, 145-153. [CrossRef]

29. Im, D.; Yang, Y.S.; Choi, H.R.; Choi, S.; Nahm, H.; Han, K.; Kim, J.K.; Cho, J.H. Prevalence of allergic disease in Korean adults: Results from the Korea national health and nutrition examination survey (2010-2012). Korean J. Otorhinolaryngol.-Head Neck Surg. 2017, 60, 504-511. [CrossRef]

30. Wangsan, K.; Chaiear, N.; Sawanyawisuth, K.; Klainin, P.; Simajareuk, K. Pattern of shiftwork and health status among nurses in a university hospital in Northeastern Thailand. Asia-Pacific J. Sci. Technol. 2019, 24, 1-11. [CrossRef]

31. McDowall, K.; Murphy, E.; Anderson, K. The impact of shift work on sleep quality among nurses. Occup. Med. 2017, 67, 621-625. [CrossRef]

32. Jalalia, M.M.; Soleimanib, R.; Jalali, S.M.; Mohisafata, B. Evaluation of the effects of allergic rhinitis treatment on sexual functioning, sleep, and fatigue parameters. Rev. Fr. Allergol. 2020, 60, 55-60. [CrossRef]

33. Sagherian, K.; Clinton, M.E.; Abu-Saad Huijer, H.; Geiger-Brown, J. Fatigue, work schedules, and perceived performance in bedside care nurses. Workplace Health Saf. 2017, 65, 304-312. [CrossRef] [PubMed]

34. Lu, Z.; Chen, L.; Xu, S.; Bao, Q.; Ma, Y.; Guo, L.; Zhang, S.; Huang, X.; Cao, C.; Ruan, L. Allergic disorders and risk of depression: A systematic review and meta-analysis of 51 large-scale studies. Ann. Allergy Asthma Immunol. 2018, 120, 310-317. [CrossRef] [PubMed]

35. Books, C.; Coody, L.C.; Kauffman, R.; Abraham, S. Night shift work and its health effects on nurses. Health Care Manag. 2020, 39, 122-127. [CrossRef] [PubMed] 